\title{
Application and viability of full-thickness coronary band grafting in equids
}

\author{
Travis Smyth 7 Imma Roquet ${ }^{7}$, Yves Plante ${ }^{2}$, Pamela Hind ${ }^{2}$, Terence Goslin ${ }^{3}$ and James L. Carmalt ${ }^{7}$ \\ 1 Department of Large Animal Clinical Sciences, Western College of Veterinary Medicine, University of Saskatchewan \\ ${ }^{2}$ Canadian Animal Genetic Resources Program, Agriculture and Agri-Food Canada, Saskatoon, SK \\ 3 Western Veterinary Services, Moose Jaw, SK, Canada
}

\begin{abstract}
Summary: The aim of the study was to determine whether a full-thickness equine coronary band graft can be successfully applied to acute wounds with excision of the coronary band and secondly, to describe the use of coronary band excision for the treatment of a clinical case of painful, abnormal hoof growth in a mature horse. Using 5 equids, a pilot study was performed in order to determine whether a $4 \mathrm{~cm}^{2}$ graft involving the skin and coronary band, on the dorsal midline of both front feet, could be transferred within and between subjects. A defect in one horse was left open as a control but was managed identically in all other respects. Limbs were immobilized in a fiberglass cast, from the ground to mid-pastern, for four weeks and subsequently monitored at pasture for nine months. After euthanasia, skin samples from the neck and surgical sites were submitted for genotype analyses. A clinical case of lameness due to a recurrent hoof crack in the hind limb, was subsequently treated by coronary band excision in the same manner as the experimental control horse. During the study all defects healed without complication and resulted in hoof horn production. There were no full thickness horn cracks and the vertical junction between the excision site (skin and keratinised horn) and parent tissue was contiguous. DNA analyses suggested that none of the grafts were accepted, despite all sites healing. The clinical case resulted in normal hoof horn growth and cessation of lameness following surgery. Coronary grafting in the horse did not result in graft take. Results suggest that removing affected horn and coronary band with subsequent immobilization could be a treatment for recalcitrant coronary band defects and abnormal horn production in the horse.
\end{abstract}

Keywords: Equine / horse / foot / hoof / graft / coronary band / traumatology

Citation: Smyth T., Roquet I., Plante Y., Hind P., Goslin T., Carmalt J. L. (2015) Application and viability of full-thickness coronary band grafting in equids. Pferdeheilkunde 31, 119-124

Correspondence: Prof. Dr. James Carmalt, Western College of Veterinary Medicine, 52 Campus Drive, University of Saskatchewan, Saskatoon, SK S7N5B4, Canada, Email: james.carmalt@usask.ca

\section{Introduction}

Lacerations of the coronary band are common and occur for a myriad reasons. The chronicity of the trauma, the amount of tissue lost, and the degree of contamination or infection, will dictate the mode of treatment in each situation (Janicek et al. 2005). If no vital structures (such as the coffin joint or tendon sheath) are damaged and the coronary band is stabilized, horses with lacerations of the coronary band have a good prognosis for healing and to return to their intended use. (Parks 1997, Janieck et al. 2005). Having said that, the time required to return to complete soundness may be as long as a year (Stashak 2002). In a large retrospective study on heel bulb and pastern lacerations (101 horses), 51/61 (84\%; for which there was follow-up information) had a successful outcome. Of the remaining 10 horses, 6 were euthanased and 4 were chronically lame. Overall $18 \%$ of the cases treated developed a hoof wall defect and $7 \%$ resulted in a chronic wound (Janicek et al. 2005).

Skin grafting the horse is a well-established procedure (Schumacher 2012). The most common indications are to speed up the healing of wounds, improve the cosmetics and resilience of a wound, or to cover wounds that are too large to heal by conventional methods (Schumacher 2012). Full-thickness free grafts can be applied immediately to wound surfaces provided that the graft bed is vascular and free of devitalized or infected tissue (Schumacher 2012). In human medicine, avulsed fingernail bed defects have been successfully treated with a number of different grafting procedures, such as split-thickness toenail grafts (Koshima et al. 2001, Sabapathy et al. 2002, Hsieh et al. 2004, Zhang et al. 2008). However, to our knowledge, there is no literature published involving the similar procedure of grafting the equine coronary band. Possible effects of coronary band grafting may include provision of epithelial or stem cells and growth factors, or simply acting as a biological dressing to improve stability of the coronary band during the healing process. Ultimately the graft may speed up healing (reducing the convalescent time by increasing the speed of epithelialization), improve the cosmetics, and allow for the return to function of patients that may not have otherwise had a successful outcome.

The hypothesis of the study was that large defects of the coronary band managed with the application of full thickness coronary band grafts and distal limb casting, could result in a good cosmetic and functional outcome (hoof horn regrowth). The objective was to determine whether a full-thickness equine coronary band graft can be successfully applied to acute wounds with excision of the coronary band and secondly, to describe the use of coronary band excision for the treatment of a clinical case of painful, abnormal hoof growth in a mature horse.

\section{Materials and Methods}

Three Quarter horses and two Welsh pony crosses free of coronary band abnormalities in the front limbs were purcha- 
sed from an auction mart. Prior to selection, a complete physical and forelimb clinical examination was performed. Horses and ponies were group housed in a barn with a cement floor and fresh straw bedding. There were two geldings and three mares ranging in age from 3 to 12 years. They ranged in weight from $350-450 \mathrm{~kg}$ and were fed hay ad libitum.

Because of the published differences in wound healing between ponies and horses, complete blinding was not achieved (Van den Boom et al. 2002). In order to minimize this bias, the pony subgroup $(n=2)$ swapped coronary grafts and a formal randomization of host-to graft matching occurred for the horse subgroup ( $n=3)$. Immediately prior to surgical intervention all horses received phenylbutazone $(4.4 \mathrm{mg} / \mathrm{kg}$, [2 mg/lb] IV) a followed by $2.2 \mathrm{mg} / \mathrm{kg}$ [1 mg/lb] SID PO for the following 5 days. A standard low four-point nerve block, using $4 \mathrm{ml}$ of $0.75 \%$ bupivacaine ${ }^{b}$ at each site, allowed desensitization of the skin of both forelimbs, distal to the metacarpophalangeal joint. Sedation was effected using a combination of $3 \mathrm{mg}$ detomidine hydrochloride ${ }^{c}$ and $3 \mathrm{mg}$ butorphanol tartrated injecte $^{d}$ intravenously. Both front limbs were clipped of hair on the dorsal aspect, from the coronary band to the metacarpophalangeal joint. An Esmarch tourniquet was placed at the level of the metacarpophalangeal joint and the area was aseptically prepared with $4 \%$ chlorhexidine gluconate ${ }^{e}$ scrub and $70 \%$ isopropyl alcohol in routine fashion.

A sterile template $(2 \mathrm{~cm}$ by $2 \mathrm{~cm}$ piece of pre-cut radiographic film) was applied to the dorsal midline of the hoof. The midpoint of the template was centered at the coronary band, at the transition between soft tissue and the hoof wall. This template was traced around its perimeter using a surgical marker ${ }^{f}$ and subsequently removed. The oscillating blade of a cast cutting saw ${ }^{9}$ was used to follow the lines marked on the skin and hoof and cut two parallel lines that were $2 \mathrm{~cm}$ apart and $1 \mathrm{~cm}$ full thickness in length through the hoof wall down to the level of the stratum internum. A third cut was made along the bottom to connect the two previous cuts. During cutting the blade was cooled using a cold saline rinse. The hoof horn was elevated by inserting a curved osteotome into the bottom cut and applying downward pressure to lever the hoof horn upwards from the underlying lamina. The horn was peeled away from the coronary band using a single lateral to medial motion as reported by Pollitt and Daradka (2004). A number 10 scalpel blade was subsequently introduced into the cuts in the hoof horn and used to continue the lines of excision proximally, following the marked line, through the coronary band and into the skin of the distal limb, to the depth of the common digital extensor tendon, extending to a point $1 \mathrm{~cm}$ proximal to the upper limit of the coronary band. The graft, which included the skin and subcutaneous tissue of the distal limb, the corium of the lamellae and the coronet, was then removed as a single unit (Pollitt and Daradka 2004), leaving the common digital extensor tendon and loose connective tissue in the wound bed exposed.

The harvested grafts were implanted according to a specific scheme (Fig. 1). The graft from the right front limb was placed in the defect on the left front limb as an autograft and the graft from the left front limb was placed in a blood-soaked gauze sponge to be used as an allograft. The autograft was maintained in position with the help of four simple interrupted sutures placed from the corners of the graft into healthy adjacent skin (top) or coronary band (abaxially at the bottom, Fig.2). To minimize movement and promote graft acceptance a $1 / 8$ inch $(3.175 \mathrm{~mm})$ thick tin plate was attached to the hoof wall, over the surgery site, using 4 or 5 small brass screws ( $3 \mathrm{~mm}$ long by $2 \mathrm{~mm}$ wide) (Fig. 3). The limb was immobilized in a fiberglass foot cast $^{\text {h }}$ for a period of 4 weeks. The cast was placed while standing and encompassed the whole foot to the level of the mid-pastern. The defect in the right front foot was filled with an allograft that had been stored for up to 25 minutes in blood soaked gauze sponges, as previously described. Each allograft was donated from the left front limb of one of the other animals in the respective subgroup (see Fig. 1). Allograft immobilization was identical to that of the opposite front limb. As a control, the open hoof horn defect in one of the horses was plated and casted, without a graft (or packing material, such as gauze) to heal by second intention. In total 4 autografts and 5 allografts were applied. The casts were checked twice daily for the presence of drainage at the top of the cast, exudation through the cast, or cast sores at the proximal margin of the cast. Horses were housed in a single group (allowed to walk around) and their vital parameters (temperature, heart rate and respiratory rate) as well as level of comfort were monitored twice per day. To reduce any periodic soreness following the procedure, phenylbutazone was used as described above. Trimethylsulfoxide ${ }^{i}$ was administered for 4 days $(30 \mathrm{mg} / \mathrm{kg}$, [13.6 mg/lb] PO BID).

After 4 weeks of cast immobilization, each of the horses was anesthetized under field conditions (using $1.1 \mathrm{mg} / \mathrm{kg}$ IV xylazine hydrochloridei and $2.2 \mathrm{mg} / \mathrm{kg}$ IV ketamine hydrochlori$\left.d e^{k}\right)$, thus facilitating cast, plate, and suture removal. At this time the healing of the horn defect was examined and judged (no bandage was applied). After cast removal the horses were monitored twice daily for the next three days, as previously described including the wounds. Following this, monthly clinical examinations and routine farrier care, in paddock condi-
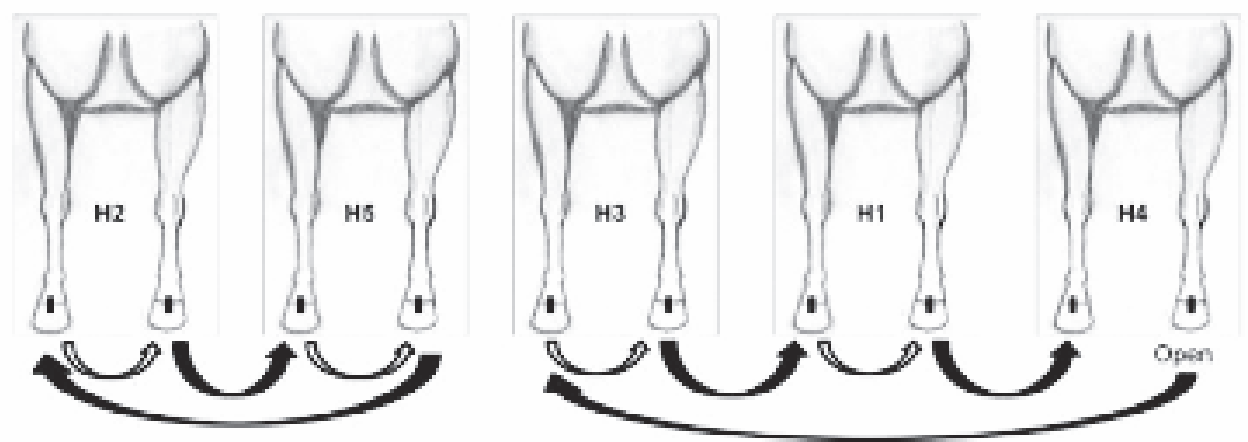

Fig. 1 Grafting pattern among the five horses. Due to healing differences in the distal limbs of ponies and horses, the animals were divided in two groups. $\mathrm{H} 2$ and $\mathrm{H} 5$ represent the welsh pony crosses, and $\mathrm{H} 3, \mathrm{Hl}$, and $\mathrm{H} 5$ represent the remaining three quarter horses. Clear arrows denote autografts within an individual, and the solid arrows denote allografts between individuals. Note, the left front leg of $\mathrm{H} 4$ remains open to serve as a control. 
tions, occurred for an additional nine months. The distal rim of advancing new horn was easily discernible as it grew down the defect in the hoof towards the sole. Given the small size of grafted tissue, sequential histological or DNA analysis to determine the fate of the grafts was not performed during this time.

Blood samples were taken from the jugular vein into EDTA tubes and the horses euthanized immediately after sample collection at 10 months post-surgery. Full thickness skin samples were harvested from grafted areas $\left(2 \mathrm{~cm}^{2}\right)$ and the lateral aspect of the mid-neck (for comparison). Equine DNA templates were prepared from the tissue samples following a modified procedure by Troy et al. (2001). Blood samples were washed using a lysis buffer was integrated for the purposes of lysis and removal of erythrocytes. This lysis buffer consisted of: $0.32 \mathrm{M}$ Sucrose, $10 \mathrm{mM}$ Tris- $\mathrm{HCl}, \mathrm{pH} 8.0$, $50 \mathrm{mM} \mathrm{KCl}$, and $0.5 \%$ TWEEN. A total of $400 \mu \mathrm{l}$ of buffer was added to $200 \mu$ l aliquots of the whole fresh blood. The leukocytes were pelleted by centrifugation and the supernatant was aspirated. Each sample was washed twice with $400 \mu$ l lysis buffer prior to DNA extraction.

Microsatellite loci were chosen based on a previous study by Glowatzki-Mullis et al. (2006) and the MoDaD microsatellite marker recommendations (Hoffmann et al. 2004). In total,

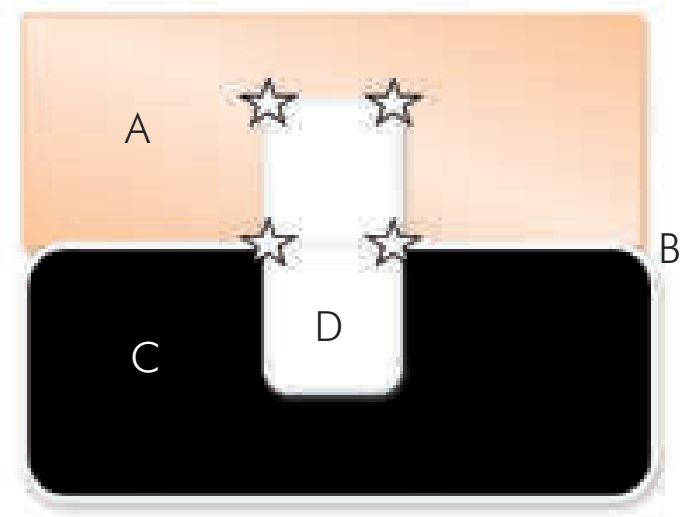

Fig. 2 Fixation of the grafts at their corners: $A=$ Skin above coronary band, $B=$ Coronary band, $C=$ Hoof horn remaining, $D=$ Horn defect, Stars = position of sutures, one on each corner. Bottom suture in graft coronary band and recipient coronary band.

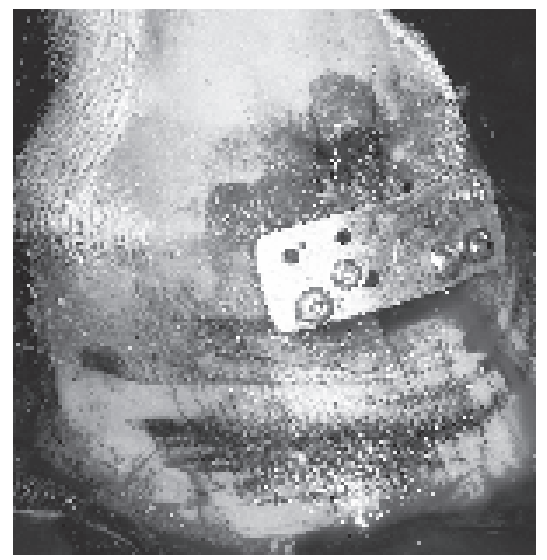

Fig. 3 A grafted limb after suture and tin-plate placement, immediately pre-casting. Note that the distal aspect of the graft, and distal sutures, are under the most proximal aspect of the plate in order to attempt to place compression on the grafted tissue.
29 microsatellite loci were genotyped (AHT5, AHT31, ASB2, ASB17, ASB43, COR7, COR22, COR69, COR71, HMS1, HMS2, HMS5, HMS6, HMS7, HMS45, HTG03, HTG04, HTG06, HTG07, HTG10, LEX34, LEX54, LEX78, TKY301, TKY325, TKY333, TKY337, TKY343, and VHL20). PCR was set up using $1 \mu \mathrm{l}$ of DNA template and a commercially available Qiagen Multiplexing PCR kit'.

Samples $(1 \mu \mathrm{l}$ of 1:50 diluted post PCR product, $0.24 \mu \mathrm{l}$ of 600-Liz size standard and $8.76 \mu \mathrm{l}$ of Hi-Di Formamide ${ }^{m}$ were denatured for 5 minutes at $95^{\circ} \mathrm{C}$, quenched on ice for 2 minutes, and loaded onto a Genetic Analyzer 3130xIm equipped with a $50 \mathrm{~cm}$ array and filled with POP7 polymer. Genotypes were determined using GeneMapper version 3.0 software ${ }^{m}$.

\section{Results}

All horses tolerated the procedure well; cast application occurred without incident and subsequent cast usage was good, despite both distal limbs being immobilized in the cast material. Upon cast removal at 4 weeks post surgery, all grafted sites had a central area of granulation tissue; however no free tissue fragments were found on the cast padding and all sutures were intact (Fig. 4). The grafted coronary band tissue was white and slightly moist to the touch of a gloved finger. The skin adjacent to the graft site was also white and soft (similar to that seen by the authors in clinical cases that have had prolonged foot casts). There was no discernible junction between grafted and normal distal limb skin. All screws in all metal plates were loose and could be digitally removed. Within 12 hours, the grafted coronary band regions had dried, darkened, and the tissue below this (within the horn defect) had hardened. There was no movement of this tissue under a gloved finger (relative to the underlying tissue or adjacent skin) and no lameness was noted. In the subsequent months, no defects were noted at the junctions of grafted (healed) coronary band tissue and horn was produced by the coronary band tissue. No obvious cracks developed between new horn

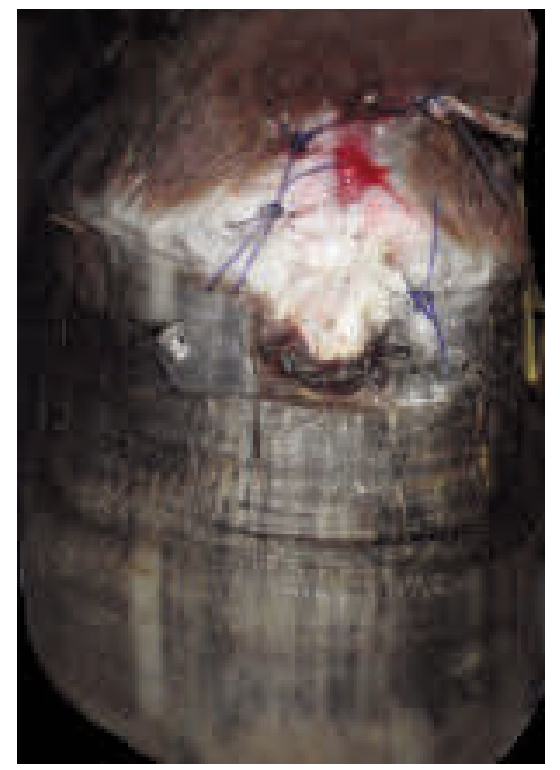

Fig. 4 The autografted foot of Horse 5 at the time of cast removal. Note the white, slightly most coronary band tissue, the central portion of granulation tissue and the presence of the sutures. 
and the remainder of the hoof horn, or within the nascent horn associated with full weight bearing when it eventually reached the solar surface. The central portion of the hoof horn was abnormally striated (in the vertical plane at all time points in four horses) but it was of normal firmness to manual touch; pressure with hoof testers, on the horn distal to the defect, was not resented. In one case, smooth white horn developed in the middle of an otherwise pigmented foot (Fig.5). No lameness was noted at any of the monthly examinations and farrier care was provided without aversion behaviour by the horses. No discernible difference was noted between the control horse and other horses, between pony group and horse group or within horse (between allo- and autografts). At the termination of the study, all tissue samples (within each horse) submitted for genotypic analysis had a homogenous genetic profile indicating that there was no foreign DNA material within the grafts.

\section{Clinical Case Management}

The coronary band excision technique was subsequently used in clinical practice for the treatment of a chronic Grade $4 / 5$ lameness related to hoof horn irregularity (Fig. 6). The 35 year old Thoroughbred gelding had injured the coronary band at an unknown time prior to veterinary assessment. The behaviour of the horse did not allow hoof care of any nature, despite attempts with heavy sedation which explained the poor condition and excessive length of the hoof wall. The horse was placed under general anaesthesia using $1.1 \mathrm{mg} / \mathrm{kg}$ IV xylazine hydrochloridei and $2.2 \mathrm{mg} / \mathrm{kg}$ IV ketamine hydrochloridei under field conditions. An Esmarch tourniquet was placed on the distal limb. The abnormal hoof horn and associated coronary band were removed in-toto using exactly the same method as used in the experimental horses. In brief, vertical cuts in the hoof horn parallel to and $1 \mathrm{~cm}$ lateral and medial to the hoof crack were made using the oscillating blade of a cast cutting sawf. The scalpel blade

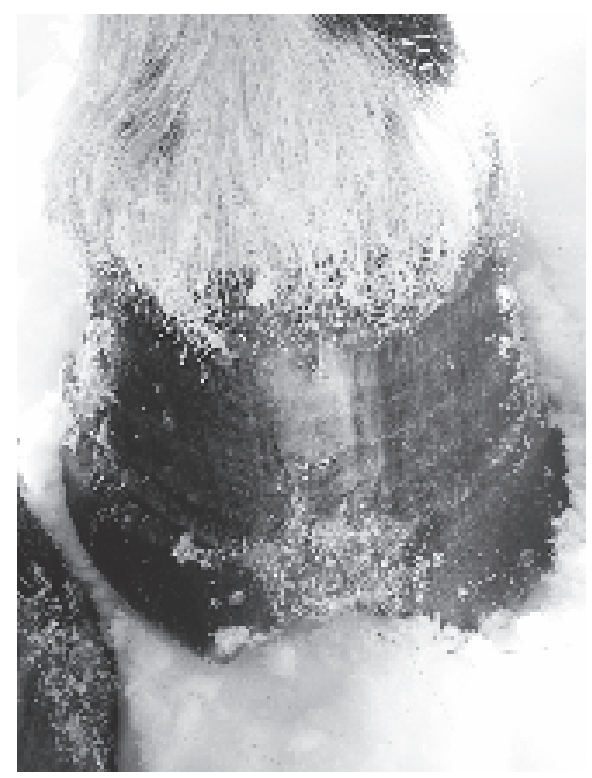

Fig. 5 The autografted foot of Horse 3. Coronary band from a white section of left hoof was moved into a region which originally contained coronary band generating black pigmented horn. Note the smooth hoof horn and abnormal pigmentation (which only occurred in this single horse). was introduced into these cuts at the level of the coronary band and the incisions continued through the coronary band into the skin of the distal limb. A short, horizontal, full skin thickness incision was used to join the vertical cuts. The abnormal horn and coronary band were removed. A metal plate was placed over the hoof wall defect (with the proximal margin parallel to the adjacent normal coronary band) and covered with a distal limb cast (encompassing the whole foot to the level of mid-pastern) for 4 weeks, as in the experimental study. During this time the horse was managed in a small outside pen with a dirt and grass footing. Lameness was difficult to assess with any degree of certainty while the limb was in a cast, but there was no apparent discomfort. Four weeks after surgery, the horse was anaesthetized to remove the cast and immediately returned to a large grass paddock. The coronary band at this time was white and moist to the touch (as was seen in the experimental horses). Eight weeks after surgery a third general anaesthesia was necessary to slightly trim exuberant horn produced from the healed coronary band (using a high-speed grinder). Assessment after the recovery from anaesthesia and immediately prior to the third general anaesthesia revealed no lameness. The horse was examined intermittently by the veterinary practitioner over the following 15 months and was not lame. The hoof horn produced is as illustrated in Figure 7.

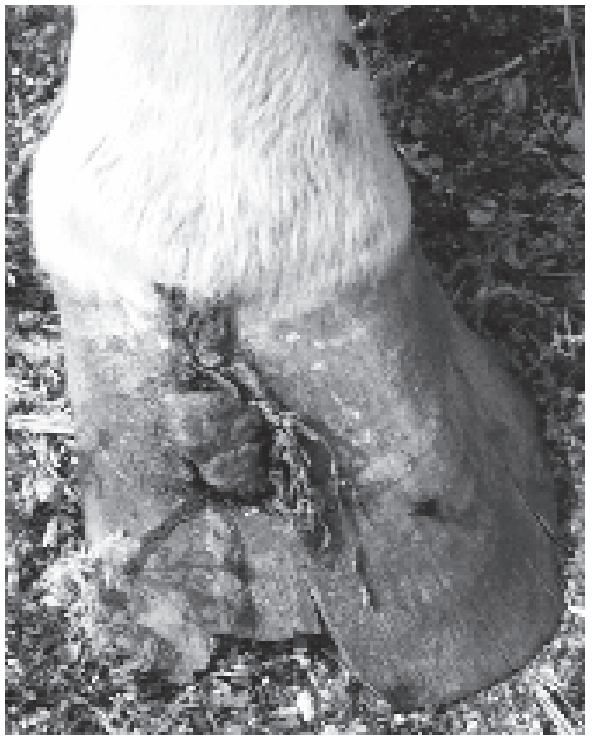

Fig. 6 The right hind limb of the 35 year old Thoroughbred with a chronic coronary band defect and abnormal hoof horn growth.

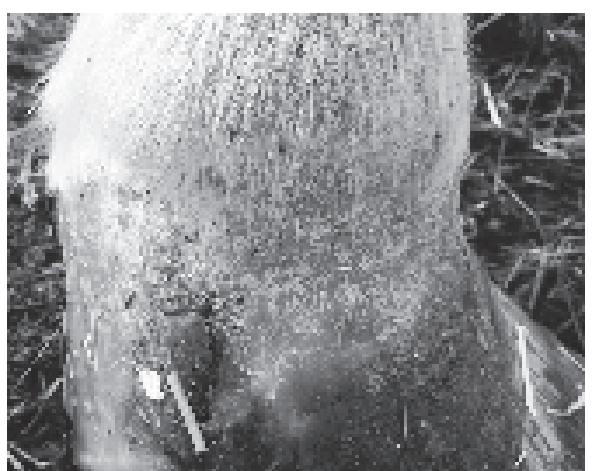

Fig. 7 The right hind limb of the same 35 year-old Thoroughbred (seen in Fig. 6) 10 months after treatment. It is possible that cracks may develop in future due to the lack of hoof management provided to this horse. 


\section{Discussion}

The study design (size of grafted tissue and cast use in the early post-operative period) as well as the low number of horses used did not allow for biopsy samples to be taken and histology to be performed. Therefore a potentially important aspect of the healing process was overlooked and the authors were unable to determine the exact fate of the autografts. Subsequent to this time period, there was no subjective difference in rate of healing or horn growth between the graft types. The results of the single non-grafted site are difficult to interpret in light of the single incidence; however our results suggest that this limb healed as well as the grafted limbs. The presence of granulation tissue at cast removal was concerning but was only present in the center of the grafted skin leading the investigators to believe that either graft rejection had occurred or that only the graft areas furthest from host blood supply and regions undergoing bridging phenomena had succumbed. One possible explanation was that only the superficial layers of the graft had failed; however if this occurred no granulation tissue was expected. The fact that all tissue samples (within horse) had the same genotypic analysis also suggests that the tissue defects healed by second intention and that the allografts were rejected. The fate of the autografted tissue is not definitively known because of the lack of sequential histological analysis.

Our results suggest that coronary band grafting was not successful. Despite this, horn restitution appeared to mirror that reported previously (Pollitt and Daradka 2004) and while there is no histological evidence to support complete removal of horn producing tissue in the experimental horses, the presence of the common digital extensor tendon at the bottom of the surgical wound would suggest that total removal had occurred. Epithelialisation from the wound margins must have resulted in restoration of the coronary band.

Graft failure can occur for a variety of reasons, many of which were possibilities in our study population (Schumacher 2012). These include inappropriate placement (graft bed not suitable such as over bone or exposed tendon, as might have occurred in our horses) or a lack of vascular supply (despite being in an area supplied by the dorsal arterial rim of the coronary band). Movement and infection may also have contributed to graft failure despite the measures taken to ameliorate both conditions. The high metabolic rate of coronary band tissue combined with the thickness and size of our graft may have resulted in anoxia and subsequent failure. It is possible that a split-thickness Meek graft (Schumacher 2012) would have been more successful in the region dorsal to the coronary band, however the authors are uncertain as to whether this technique would be useful at the coronary band. Finally, allografted tissue (but not autografts) is likely to have been subjected to immunological rejection. The reason the authors chose to include this grafting option was that in the event of graft success, future use of the technique in clinical situations may have required tissue banking as donor site morbidity from autograft tissue was likely going to be a concern (Schumacher et al. 1987). The fact that the control limb healed, leads to the conclusion that the coronary band can be reconstituted by epithelialisation from the wound margins in the $2 \mathrm{~cm}$ wide defects. Given this finding, the persistence of hoof cracks originating from an initial coronary band injury are most likely caused by persistent infection and, or, failure to provide mechanical stability (immobilization) while the initial area of disruption grows out. The need for a dorsal metal plate in our experimental horses (and the clinical case) is not proven. The cuts in the hoof horn did not reach the solar surface, despite which the authors were concerned about slight flexing of the coronary band associated with the tissue removal. Plate placement may not be necessary and might be omitted in future clinical cases. However, it is felt that immobilization of the foot in a cast to the mid-pastern level is necessary and that including the limb proximal to the coronary band results in greater hoof stability, although this is conjecture. It is possible that there may be a front, hind limb difference in coronary band healing, due to differing forces acting on them; however our study design did not test this hypothesis.

Despite the fact that it appears that the grafts were not accepted, a good cosmetic and functional outcome (hoof horn regrowth) was realized. The authors created a large $(2 \mathrm{~cm}$ wide) dorsal midline, full thickness (down the level of the common digital extensor tendon) defect completely devoid of horn producing tissue. The size was subjectively chosen to be considerably larger than a defect the horse could heal by second intention. Also, by being void of coronary band tissue (in the non-grafted defect) no horn growth was expected. Intriguingly, all of the wounds healed, irrespective of the presence of a graft and results suggest that second intention healing occurred. Therefore horses with chronic defects in the coronary band, producing irregular horn and hoof cracks, may respond positively to en-bloc resection of the affected coronary band. This theory was subsequently tested in a horse that did not allow any routine hoof care. In that animal, treatment of a clinical hoof defect by en-bloc resection was successful. While this is only a single animal, the results are encouraging and the authors are seeking to determine whether this technique will work in future clinical cases. Further studies are ongoing to determine the fate of coronary band autografts histologically and to examine the temporal healing order in non-grafted sites.

Overall the coronary band grafting was unsuccessful. However, excision of the coronary band provided a functional result in a patient with a chronic disruption and may be a useful treatment option in select cases.

\section{Acknowledgement}

This research was funded the Equine Health Research Fund, Western College of Veterinary Medicine.

\section{Animal Welfare Statement}

This work was approved by the University of Saskatchewan Animal Use Committee and adhered to the Canadian Council on Animal Care guidelines for humane animal use (ANI 20100015).

\section{Conflicts of interest}

The authors exclude any conflict of interest. 


\section{Manufacturer's addresses}

a Butequine, Bioniche Animal Health, Belleville, Ontario, Canada.

b Marcaine (0.75\%), bupivicaine HCL, Hospira Healthcare Corp, Montréal, QC

c Dormosedan 10mg/ml, Pfizer Animal Health, Kirkland, QC, Canada

d Torbugesic $10 \mathrm{mg} / \mathrm{ml}$, Wyeth Animal Health, Guelph, ON, Canada

e Chlorhexidine gluconate, Stanhexidine, Omega Laboratories, Montréal, QC, Canada

f DYNJSMOI Surgical skin marker, Medline Industries Inc, Mundelein, IL, USA

9 M-Pact Cast Removal System, American Orthopedic, Eudora KS, USA

h Delta-Lite Plus, BSN Medical Inc, Rutherford College, NC, USA

i Apo-Sulphatrim-DS, 960mg tablets, Apotex Inc. Toronto, Canada

i Xylamax, 100mg/ml, Vetoquinol N.-A lc. Lavaltrie, QC, Canada

k Vetalar, Bioniche Animal Health Canada, ON, Canada

I Qiagen Inc., Burlington, Ontario, Canada.

m Applied Biosystems, Foster City, CA, USA

\section{References}

Glowatzki-Mullis M. L., Muntwyler J., Pfister W., Marti E., Rieder S., Poncet P. A., Gaillard C. (2006) Genetic diversity among horse populations with a special focus on the Franches-Montagnes breed. Animal Genetics 37, 33-39

Hoffmann I., Ajmone Marsan P., Barker S. F. (2004) New MoDaD marker sets to be used in diversity studies for the major farm animal species: recommendations of a joint ISAG/FAO working group. Proc 29th International Conference on Animal Genetics, Tokyo, Japan. 107

Hsieh S., Chen S., Chen T., Cheng T. Y., Wang H. J. (2004) Thin split-thickness toenail graft for avulsed nail bed defects. Ann. Plast. Surg. 52, 375-379

Janicek J. C., Dabareiner R. M., Honnas C. M., Crabill M. A. (2005) Heel bulb lacerations in horses: 101 cases (1988-1994). J. Am. Vet. Assoc. 226, 418-423

Koshima I., Itoh S., Takahashi Y., Nanba Y., Kishimoto K. (2001) Free vascularised nail graft under digital block. Reconstr. Microsurg. $17,559-601$

Parks A. H. (1997) Wounds of the equine foot: principles of healing and treatment. Equine Vet. Educ. 9, 317-327

Pollitt C. C., Daradka M. (2004) Hoof wall wound repair. Equine Vet. J. 36, 210-215

Sabapathy S., Venkatramani H., Bharathi R., Jayachandran S. (2002) Reconstruction of finger tip amputations with advancement flap and free nail bed graft. J. Hand Surg. [Br]. 27, 134-138

Schumacher J., Chambers M., Hanselka D. V., Morton L. D. (1987) Preservation of skin by refrigeration for autogenous grafting in the horse. Vet. Surg. 16, 358-361

Schumacher J. (2012) Skin grafting. In: Equine Surgery 4th Edn. Aver and Stick (eds). Elsevier, St. Louis Missouri, 285-305

Stashak T. S. (2002) Lameness: Part 1 The Foot. In: Adams' Lameness in horses 5th Edn. Stashak TS (ed). Baltimore MD. Lippincott Williams \& Wilkins. 725-732

Troy C. S., MacHugh D. E., Bailey J. F., Magee D. A., Loftus R. T., Cunningham P., Chamberlain A. T., Sykes B. C., Bradley D. G. (2001) Genetic evidence for near eastern origins of European cattle. Nature 410, 1088-1091

Van Den Boom R., Wilmink J. M., O'Kane S., Wood J., Ferguson M. W. J. (2002) Transforming growth factor-beta levels during secondintention healing are related to the different course of wound contraction in horses and ponies. Wound Rep. Regen.10, 188-194
Zhang G. L., Guo A., Zhang M., Xu Z. Y., Zhang L. Z., Wang S. B., Li J., Wu F. L., Yu H. (2008) One-stage toenail lengthening: a report of 9 cases. Zhongguo Gu Shang. (Chin. J. orthop. traumat.) $21,47-48$

Erweiterte Zusammenfassung

\section{Anwendung und Überlebensfähigkeit eines Kronsaum- transplantats bei Equiden}

Die Hauttransplantataion ist auch beim Pferd eine eingeführte Methode. Die häufigsten Indikationen sind Beschleunigung der Wundheilung, Verbesserung der Kosmetik und Widerstandskraft einer Wunde oder die Abdeckung von Wunden, die für eine konventionelle Abheilung zu groß sind. Freie Hauttransplantate können direkt auf Wunden aufgebracht werden, vorausgesetzt das Wundbett ist durchblutet und frei von Debris oder infizierten Gewebe. Beim Menschen konnten Defekte des Nagelbetts erfolgreich mit verschiedenen Transplantationstechniken behandelt werden. Nach Kenntnis der Autoren wurde bisher keine vergleichbare Technik zur Transplantation des Kronsaums beim Pferd veröffentlicht. Mögliche positive Effekte einer Kronsaumtransplantation könnten die Versorgung der Wunde mit Epithel- oder Stammzellen und Wachstumsfaktoren sein oder sie wirkt einfach als Gewebsabdeckung zur Stabilisierung des Kronsaums während des Heilungsprozesses. Das Transplantat könnte durch Beschleunigung der Epithelisation die Rekonvaleszenz verkürzen, das kosmetische Ergebnis verbessern und für solche Patienten eine funktionelle Heilung gewährleisten, die sonst nicht befriedigend behandelt werden können.

In einer Pilotstudie an fünf Equiden sollte untersucht werden, ob ein $4 \mathrm{~cm}^{2}$ großes Haut- und Kronsaumstück der dorsalen Mitte des Vorderbeins zwischen zwei Pferden mit Erfolg transplantiert werden kann. Die Gliedmaßen wurden nach der Transplantation über 4 Wochen in einem vom Boden bis zur mittleren Kronbeinregion reichenden Fiberglasverband ruhiggestellt und in der Folge über 9 Monate auf der Weide kontrolliert. Nach der Euthanasie wurden für die genotypische Analyse Hautproben vom Hals und von den Operationsstellen entnommen. Ein klinischer Fall von Lahmheit aufgrund eines rezidivierenden Hornspalte wurde in derselben Weise wie die Versuchspferde behandelt. In der Studie heilten alle Horn-Kronsaumdefekte unter Hornproduktion komplikationslos ab und es kam zu keinen Hornbrüchen. Obwohl alle Wunden abheilten, wiesen die DNA-Analysen jedoch darauf hin, dass keines der Transplantate angenommen wurde. Der klinische Fall resultierte in normalem Hornwachstum und die Lahmheit verschwand.

Das Ergebnis der Untersuchung zeigt, dass Fälle von Kronsaumverletzungen mit Substanzverlust und abnormer Hornproduktion durch Entfernung des losen Horns und Kronsaumgewebes mit anschließender Immobilisation zufriedenstellend behandelt werden können. Weil die Transplantate aber nicht angenommen wurden, war die Kronsaumtransplantation insgesamt gesehen erfolglos. Die Exzision von Kronsaumgewebe kann jedoch in ausgewählten chronischen Fällen von Kronsaumdefekten mit Hornwachstumsstörungen eine brauchbare Therapie darstellen.

Schlüsselwörter: Pferd / Huf / Zehe / Transplantation / Kronsaum / Hornspalt / Traumatologie 